\title{
Urinary Incontinence: Diagnosis and Treatment in the Elderly
}

\author{
Joy A. Greer • Lily A. Arya • Ariana L. Smith
}

Published online: 27 February 2013

(C) Springer Science+Business Media New York 2013

\begin{abstract}
Urinary incontinence is a prevalent condition among the elderly. History and physical exam are helpful in delineating the specific type or types of urinary incontinence present. When beginning treatment, clinicians should consider functional status, comorbidity, and goals of therapy. Therapeutic options include behavioral therapy, physical therapy, pharmacologic management, neuromodulation, mechanical devices, and surgery. The treatment options with the most data in the elderly are behavioral therapy and antimuscarinic medications, both showing effectiveness. Limited data are available for the other modalities, but generally show that they are effective in older patients. In this update, data from many recent meta-analyses and systematic reviews are synthesized to help guide treatment decisions for elderly patients suffering from urinary incontinence.
\end{abstract}

Keywords Antimuscarinic medication - Behavioral therapy $\cdot$ Beta-3 agonist $\cdot$ Biofeedback $\cdot$ Botulinum toxin . Cognitive impairment $\cdot$ Diagnosis · Elderly $\cdot$ Female $\cdot$ Frail . Magnetic therapy $\cdot$ Male $\cdot$ Mixed urinary incontinence . Nerve stimulation · Neuromodulation - Overactive bladder . Pelvic floor muscle therapy $\cdot$ Penile clamp $\cdot$ Periurethral

J. A. Greer $(\bowtie) \cdot$ L. A. Arya

Hospital of the University of Pennsylvania, Division of Urogynecology, Department of OB-GYN, University of Pennsylvania, 3400 Spruce Street; 1000 Courtyard Building, Philadelphia, PA 19104-4283, USA

e-mail: joy.greer@uphs.upenn.edu

L. A. Arya

e-mail: larya@obgyn.upenn.edu

\section{A. L. Smith}

Hospital of the University of Pennsylvania, Division of Urology, Department of Surgery, University of Pennsylvania, 299 South 8th Street, Philadelphia, PA 19106, USA

e-mail: ariana.smith@uphs.upenn.edu bulking agents $\cdot$ Pessary $\cdot$ Postprostatectomy urinary incontinence $\cdot$ Sling $\cdot$ Stress urinary incontinence $\cdot$ Urgency urinary incontinence

\section{Introduction}

Urinary incontinence (UI) is the complaint of involuntary loss of urine [1•]. Prevalence increases with age, making it a considerable public health concern for the elderly, given the forecasted population growth among those over 65 years [2, 3]. The impact of UI on health-related quality of life is substantial, and is associated with comorbid conditions, institutionalization and mortality [4].

The most common type of UI to affect both elderly men and women is urgency urinary incontinence (UUI), the complaint of involuntary loss of urine associated with sudden, compelling desire to pass urine which is difficult to defer $[1 \bullet]$. Other types of UI reported by older men and women include nocturnal enuresis, continuous incontinence, or insensible urinary incontinence when the patient is unaware of how UI occurred [1•]. Stress urinary incontinence (SUI), the complaint of involuntary loss of urine on effort or physical exertion (sporting activities), or on sneezing or coughing, and mixed urinary incontinence (MUI), the complaint of both UUI and SUI, predominately affects women [1•]. UUI and MUI are often accompanied by symptoms of overactive bladder $(\mathrm{OAB})$, including urinary frequency, urgency, and nocturia. Post-prostatectomy UI in men can range from 5-60\%, depending on the definition of UI used and the type of treatment administered, but has been decreasing in contemporary studies with improved understanding of prostatic anatomy, surgical technique and localization of applied therapies [5]. UI does improve within the first year following prostate 
treatment, so understanding natural history of the healing process is important in planning interim therapy [6•].

Severity of UI in the elderly can wax and wane, and may be depended on exacerbations of concomitant disease processes, medications and proximity to ancillary procedures or treatments. The aim of this update is to review newly published data to guide clinicians in diagnosis and treatment of UI in the elderly patient.

\section{Diagnosis}

The specific type of UI can generally be elicited by thorough history and physical exam, with complex clinical scenarios requiring urodynamic testing for definitive diagnosis.

The review of systems should screen for other conditions that may make the patient's treatment more complex. For men with pain, hematuria, recurrent infections, suspected or proven incomplete bladder emptying, or incontinence following pelvic irradiation, specialty evaluation is recommended. Additional factors in women prompting further evaluation include significant pelvic organ prolapse, persistent incontinence or recurrent incontinence after previous incontinence surgery, history of pelvic irradiation, prior radical pelvic surgery, and suspected fistula [7••].

The examination for UI is best performed with the patient's bladder comfortably full to observe the involuntary loss of urine, either urethral or extraurethral. Observation of involuntary leakage from urethra on coughing or valsalva is strongly suggestive of SUI, whereas the observation of involuntary leakage from the urethra with the sensation of a sudden, compelling desire to void that is difficult to defer is highly suggestive of UUI [ $1 \bullet]$. Extraurethral incontinence, highly suggestive of a genitourinary fistula, is the observation of urine leakage through channels other than the urethral meatus. In addition to a directed exam trying to elicit UI, the innervation of the sacral nerve roots (S2-S4) should be evaluated and more generalized neurologic exam should be performed as indicated. The abdominal exam should explore signs of bladder fullness, the presence of other abdominal masses or ascites, and scars indicating previous relevant surgery or trauma. The flank area should be examined to assess for renal tenderness and masses.

A detailed pelvic exam should be performed in the female patient, evaluating the presence of atrophic vaginitis, hypermobility of anterior vaginal wall, and prolapse of pelvic organs. The urethra should be evaluated for erosion in patients who have had prolonged indwelling catheters, and to rule out abnormalities including urethral diverticuli. In both sexes, a rectal exam should be performed to evaluate anal sphincter tone, the presence of masses, the presence or absence of fecal impaction, and the size and nodularity of the prostate in male patients. The pelvic floor muscles should be evaluated at baseline and with a voluntary or reflex contraction, to determine if the response is strong, normal, weak, or absent.

Initial office evaluation should include post-void residual measurement, urine analysis, microscopy, and urine culture with sensitivity if indicated. Additional evaluation that may be helpful in diagnosis and management of UI includes a 24-48 hour bladder diary, where a patient records the time of each micturition, the volume of each void, fluid intake, pad usage, number and severity of incontinence episodes for at least 24 hours. The use of patient self-reported questionnaires, such as the International Consultation on Incontinence Questionnaire (ICIQ) [8] or urodynamics, can be helpful to clarify the type of UI if it is still unclear after a thorough history and physical exam.

\section{Treatment}

When initiating treatment for UI in older patients, several factors need to be considered. A patient's comorbidities, current medication use, life expectancy, preferences for care, and goals of care (both for the patient and potential caregivers) should be considered when choosing therapy, especially in frail elderly patients with UI $[9 \cdot \bullet]$.

The following reversible causes of UI should be investigated in each individual patient and treated if found: delirium, urinary tract infection, polyuria, restricted mobility and fecal impaction. Medications such as diuretics, antidepressants, anti-psychotics, $\alpha$-blockers, and $\alpha$-agonists have all been shown to cause or exacerbate urinary incontinence, and should be evaluated to determine whether alternate medications could be used to decrease UI [10].

\section{Behavioral Modification}

Behavioral modifications such as caffeine restriction, fluid manipulation if patients have excessive fluid intake, and bladder retraining through timed voiding are beneficial first line treatments for UI [11]. Fluid restriction should be avoided in long-term care residents and other frail elders who may not have ready access to fluids or accurately sense thirst $[9 \bullet \bullet$. Timed voiding and habit training are particularly important aspects of treatment for nursing home residents [9••]. For obese women, weight loss is helpful in conjunction with exercise and behavioral modification to decrease UI [12]. Adding pelvic floor muscle exercises to behavioral therapy resulted in significant decreases in OAB symptoms [13]. Combinations of behavioral treatments are more effective than just one [14]. In a recent Cochrane review [15], UUI symptom improvement is greater when behavioral modification is combined with an antimuscarinic than either therapy alone. 


\section{Physiotherapy Treatment}

\section{Pelvic Floor Muscle Training}

Pelvic floor muscle training (PMFT) has been prescribed for over 60 years to improve both SUI and UUI. PMFT require tightening of the pelvic muscles and holding the contraction for a few seconds, followed by a rest period. PMFT may prevent urgency and UUI by inhibiting and aborting inappropriate detrusor contractions [16], while stimulating the guarding reflex in adults with SUI [17].

Dumoulin and Hay-Smith [18••] concluded in their Cochrane review that PFMT should be included in first-line conservative management programs for women with SUI, UUI or MUI. The treatment effect seemed to be greater in women with SUI alone, who participated in a supervised PFMT program for at least 3 months.

A recent Cohrane review [19••] evaluated the impact of PFMT with or without biofeedback for men who had urinary incontinence after radical prostatectomy. Findings were conflicting; limited benefit was seen in improving UI in studies that aimed at both treatment and prevention.

\section{Biofeedback}

Pelvic floor biofeedback uses surface perineal electrodes or vaginal or rectal cones to monitor external urinary sphincter or levator ani muscle activity during PMFT. Biofeedback provides the patient and the practitioner with visible cues indicating proper isolation and contraction of the muscle group being exercised. Biofeedback may be more effective than placebo or PFMT in reducing UI [20, 21••].

\section{Electrical Stimulation}

Vaginal electrical stimulation has been used in the treatment of both SUI and UUI. There is considerable variation in devices, electrical parameters and recommended frequency of treatment $[22,23]$. Data on efficacy is conflicting [22-25], and a significant placebo effect may exist.

\section{Vaginal Cones}

In a randomized controlled trial, vaginal cone therapy showed no increased benefit above PFMT for the treatment of postmenopausal SUI [26].

\section{Medications}

There are currently no FDA approved medications for SUI in the United States. Imipramine and duloxetine have been studied as off-label therapies for SUI, but should not be used in elderly patients $[9 \bullet \bullet$.

\section{Pharmacologic Therapies for UUI}

Antimuscarinics

Antimuscarinic medications, which act on the filling-storage phase by inhibiting afferent input from the bladder and directly inhibiting smooth muscle contractility, are the most commonly used pharmacotherapy for UUI when conservative treatment is inadequate to control symptoms [15]. The efficacy of tricyclic antidepressants, $\alpha$-adrenergic agonists, afferent nerve inhibitors, prostaglandin antagonists, $\beta$ adrenergic agonists, and calcium channel blockers versus antimuscarinics for UUI has not been compared in well designed randomized clinical trials. These medications are used sparingly [27].

Common side effects from antimuscarinic medications include dry mouth, blurred vision, confusion, constipation [28] and rarely increased heart rate[29] as muscarinic receptors are also present in other body tissues. Discontinuation rates have been reported as high as $71 \%$ [30].

Oxybutynin, tolterodine, trospium, solifenacin, darifenacin, and festoterodine are the antimuscarinic medications currently available in the United States. Table 1 summarizes each medication, dosage and elderly-specific information (Table 1). In a recent meta-analysis of the adverse event profiles for antimuscarinics, the profiles for darifenacin, festoterodine, transdermal oxybutinin, solifenacin, tolterodine and tropsium chloride are similar though oral oxybutynin had a higher rate of dry mouth and constipation. The most common reported adverse event was dry mouth [32].

Although drug absorption does not differ with age, drug distribution may change due to decreased muscle mass, decreased water content, and renal impairment. The bloodbrain barrier may be more permeable in elderly patients secondary to comorbidities and other medications, increasing the rate of central nervous system side effects [33•]. There are relatively little data on the central nervous system safety in the elderly $[33 \bullet, 34 \bullet \cdot]$, and prior clinical trials have not adequately screened, measured, and documented CNS symptoms [34・•].

In the few trials reporting specifically on the efficacy of antimuscarinic medications in elderly populations, healthy older patients seem to have similar efficacy without an increase in serious adverse effects or side effect profiles when compared with younger women [35-37]. Some studies however suggest that antimuscarinics may be effective at lower doses in frail older persons due to pharmacokinetic

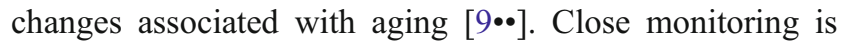
needed when prescribing these medications to older 
Table 1 Dose, adverse reactions*, and elderly-specific data on antimuscarinic medications

\begin{tabular}{|c|c|c|c|}
\hline Generic Name & Dose & Adverse Reactions (>10 \%) & Elderly-Specific data \\
\hline Darifenacin & $7.5-15 \mathrm{mg}$ daily & $\begin{array}{l}\text { Dry mouth (19\% to } 35 \%) \\
\text { Constipation }(15 \% \text { to } 21 \%)\end{array}$ & $\begin{array}{l}\text { No known effects on cognitive function } \\
\text { Avoid in patients with severe hepatic impairment [37] }\end{array}$ \\
\hline Fesoterodine & 4-8 mg daily & Dry mouth (19 \% to $35 \%$; dose related $)$ & $\begin{array}{l}\text { 24-month data showing tolerability and efficacy [44, } \\
45]\end{array}$ \\
\hline \multirow[t]{5}{*}{ Oxybutinin IR } & \multirow[t]{5}{*}{$\begin{array}{l}5 \mathrm{mg} \text { two to four } \\
\text { times daily }\end{array}$} & Dizziness ( $4 \%$ to $17 \%)$ & $\begin{array}{l}\text { No significant difference in tolerability and efficacy } \\
\text { when compared to solifenacin [41] }\end{array}$ \\
\hline & & Somnolence $(2 \%$ to $14 \%)$ & \multirow[t]{4}{*}{ Impaired memory recall and immediate learning [31] } \\
\hline & & Dry mouth (29\% to $71 \%$; dose related) & \\
\hline & & Constipation ( $7 \%$ to $15 \%)$ & \\
\hline & & Nausea $(2 \%$ to $12 \%)$ & \\
\hline \multirow[t]{3}{*}{ Oxybutinin ER } & \multirow[t]{3}{*}{ 5-30 mg daily } & $\begin{array}{l}\text { Dizziness }(4 \% \text { to } 17 \%) \text {, somnolence } \\
\quad(2 \% \text { to } 14 \%)\end{array}$ & \multirow[t]{3}{*}{$\begin{array}{l}\text { No worsening of cognitive function in cognitively } \\
\text { impaired women during } 4 \text { week trial }[38 \cdot]\end{array}$} \\
\hline & & $\begin{array}{l}\text { Dry mouth }(29 \% \text { to } 71 \% \text {; dose related }) \\
\text { constipation ( } 7 \% \text { to } 15 \%)\end{array}$ & \\
\hline & & Nausea $(2 \%$ to $12 \%)$ & \\
\hline $\begin{array}{l}\text { Oxybutinin } \\
\text { transdermal } \\
\text { patch }\end{array}$ & $\begin{array}{l}\text { One patch every } \\
\text { three to four days }\end{array}$ & Local skin irritation, pruritus (14\%) & No specific data in elderly \\
\hline $\begin{array}{l}\text { Oxybutynin } \\
\text { transdermal gel }\end{array}$ & 1g gel daily & None reported at rates $>10 \%$ & No specific data in elderly \\
\hline \multirow[t]{2}{*}{ Solifenacin } & \multirow[t]{2}{*}{$5-10 \mathrm{mg}$ daily } & Dry mouth (11\% to $28 \%$; dose-related) & \multirow[t]{2}{*}{$\begin{array}{l}\text { No significant difference in tolerability and efficacy } \\
\text { when compared to oxybutinin [41] }\end{array}$} \\
\hline & & Constipation ( $5 \%$ to $13 \%$; dose-related) & \\
\hline Tolterodine IR & $1-2 \mathrm{mg}$ twice daily & Dry mouth $(35 \%)$ & Adherence twice as long as oxybutinin [39] \\
\hline Tolterodine ER & 2-4 mg daily & Dry mouth $(23 \%)$ & \\
\hline Trospium IR & $20 \mathrm{mg}$ twice daily & Dry mouth ( $9 \%$ to $22 \%)$ & $\begin{array}{l}\text { Positively charged, hydrophilic quaternary amine } \\
\text { unable to cross blood-brain barrier [36] }\end{array}$ \\
\hline \multirow[t]{2}{*}{ Trospium ER } & \multirow[t]{2}{*}{$60 \mathrm{mg}$ daily } & \multirow[t]{2}{*}{ Dry mouth ( $9 \%$ to $22 \%)$} & $\begin{array}{l}\text { Use with caution in renal impairment; no specific dose } \\
\text { adjustment just for age needed }\end{array}$ \\
\hline & & & $\begin{array}{l}\text { ER formulation has fewer side effects than IR } \\
\text { formulation }\end{array}$ \\
\hline
\end{tabular}

*Adverse reaction data obtained from drug prescribing information unless otherwise noted; IR = immediate release; ER = extended release

patients, and unlike in younger patients, combinations of bladder antimuscarinics should not be used [9・•]. Furthermore, physicians should be aware of the additive antimuscarinic effect of medications used to treat Parkinson's disease or dementia when treating patients with UUI.

Some recent studies of antimuscarinics in elderly subjects are worth mentioning.

Lackner et al. [38•] recently published results of a randomized controlled trial of the efficacy of oral extendedrelease oxybutynin in cognitively impaired older women with UUI in a nursing home setting. In the absence of a behavior training program, oxybutynin had no increased benefit over placebo regardless of cognitive or functional status. However, there was also no worsening of cognitive status or other significant differences in the safety profiles in this 4-week trial.
In a database study looking a claims data, tolterodine was continued for almost twice as long compared to oxybutynin in elderly patients although less that half of patients continued therapy in either group 6 months after initiating treatment [39]. In a study of a health care claims database, there was no significant difference in falls, hospital visits for fracture or delirium in the first 90 days after elderly patients initiated either tolterodine or oxybutynin. There was a slight increased risk in hospitalization for any cause or death for any cause in the oxybutynin group. As outcomes were exploratory in nature and effect sizes were relatively small, the authors recommended interpreting these findings with caution [40].

In a recent sub-analysis [41], there was no significant difference in the tolerability of solifenancin and oxybutynin immediate-release between older ( $>65$ years) and younger ( $\leq 65$ years) patients. 
Recent large studies $[42,43]$ have reported that fesoterodine $8 \mathrm{mg}$ was superior to extended-release tolterodine $4 \mathrm{mg}$ for UUI episodes and other outcomes as early as 3 weeks and have also now demonstrated the continued efficacy and tolerability of this drug for 24 months regardless of age [44, 45].

\section{$\beta-3$ Agonists}

A $\beta-3$ agonist, mirabegron [46], is available for use in Japan and has recently been approved by the FDA for use in the United States. This drug stimulates the $\beta-3$ adrenergic receptors, the predominate receptors of the detrusor muscle [47], to improve relaxation during the storage phase of micturition [47]. Early results show mirabegron to be more effective than placebo in treating OAB [48, 49]. Common antimuscarinic side effects were reported less frequently for individuals receiving mirabegron than with tolterodine extended-release but dizziness and palpatations were slightly higher. No increase in cardiovascular adverse events in the short-term studies completed thus far has been noted, although small significant changes in blood pressure and heart rate were seen. Long-term safety data, especially in elderly patients, are needed $[46,50]$.

\section{Botulinum-A Toxin}

Injection of botulinum toxin into the detrusor muscle is approved by the FDA for the treatment of neurogenic $\mathrm{OAB}$. Botulinum toxin(BoNT/A) is a potent neurotoxic protein that inhibits detrusor contractions are inhibited by blocking the release of achetylcholine and other neurotransmitters [51]. BoNT/A may also decrease sensory input to the bladder by down-regulating the receptors of afferent neurons in the detrusor muscle [52]. Commonly, under local anesthesia with cystoscopic guidance, 100-200 units of $\mathrm{BoNT} / \mathrm{A}$ is delivered via multiple injections into the detrusor muscle or submucosa of the bladder, sparing the trigone. To maintain efficacy, injections may need to be repeated every 3-12 months. Procedural risks include gross hematuria $(\leq 10 \%)$ [53], urinary tract infection $(\leq 22 \%)$ [53], pain, and increased post-void residual requiring de novo intermittent self-catheterization [54••]. Transient and mild neurologic side effects $(\leq 10 \%)$ have also been reported [55]. Rare systemic side effects such as diffuse muscle weakness have also been reported (1\%) [56] and usually resolve within a few months.

Although BoNT/A can improve symptoms of OAB, a Cochrane review [57] concluded that too little data exist on safety and efficacy compared with placebo and other treatments. BoNT/A injections have been showed to be significantly more successful in patients with anticholinergic intolerability, as compared to patients with poor medication efficacy [58]. In a phase 2 double-blind, randomized trial [59] comparing a single dose (100 units or 150 units) of BoNT/A to placebo in adults with refractory OAB, up to 65 $\%$ of patients had more than $50 \%$ improvement with BoNT/A, with minimal rates of urinary tract infection and urinary retention. In a randomized trial of BoNT/A injection versus oral anticholinergic medication in women with idiopathic UUI who were not refractory to treatment, Visco et al. [60 • $]$ reported similar efficacy in reduction of UUI episodes (3.4 in the anticholinergic group and 3.3 in the BoNT/A group, $p=0.81$ ) and quality of life improvement. However, the reported dry rate in the BoNT/A group $(27 \%)$ was twice the dry rate of the anticholinergic group $(13 \%, p=0.003)$. The BoNT/A group was less likely to have dry mouth, but had higher rates of transient urinary retention and urinary tract infections. A clear consensus on the use of the drug in clinical practice including optimal dose, location and number and timing of initial and repeat injections, has not been determined. No trials of BoNT/A specifically address the elderly. Special concerns regarding the use of BoNT/A in the elderly include increased risk of post-procedure urinary retention due to impaired bladder contractility and reduced dexterity and ability to perform clean intermittent self-catheterization. Although Allergan is seeking FDA approval for a 100 unit BoTN/A dose for idiopathic OAB, currently its use is off-label and should be restricted to patients who have failed conservative therapies [61].

\section{Estrogen}

Loss of estrogen on urogential tissue, including thinning of mucosa, loss of sphincter muscle tone, and alteration of the urethrovesical angle, may contribute to the increased prevalence of $\mathrm{OAB}$ in postmenopausal women [62]. Vaginal estrogen improves symptoms of urgency and frequency in postmenopausal women, but neither vaginal nor oral estrogen has been shown to be effective for UUI [63-66].

\section{$\alpha$-Adrenergic Blockers}

Several randomized trials have shown that in elderly men with benign prostatic hyperplasia being treated with an $\alpha$-blocker, the addition of an anticholingeric can improve persistent $\mathrm{OAB}$ symptoms with minimal side effects [67-69].

\section{Neuromodulation}

A second-line therapy for UUI involves neuromodulation of the nerves supplying the detrusor and pelvic floor muscles, after a patient has failed behavioral and pharmacologic interventions. 


\section{Peripheral Nerve Stimulation}

Percutaneous tibial nerve stimulation (PTNS) that delivers neuromodulation to the pelvic floor via the posterior tibial nerve is a potentially promising treatment for the elderly with UUI. A fine needle electrode is inserted slightly above the ankle to access the tibial nerve. This anatomical area has projections to the S2S4 junction of the sacral nerve plexus, creating a feedback loop that modulates bladder innervation [70, 71].

PTNS significantly decreases severity of UUI and improves health-related quality of life when compared to placebo $[72,73]$. In a recent meta-analysis [74•], the short-term efficacy of PTNS was comparable to drug therapy for OAB and UUI. The effects of 12 weekly 30-minute intervention sessions are usually reported; however, patients with improvement may continue treatment at individually based greater intervals for sustained symptom relief. Studies specifically evaluating the effectiveness of PTNS in treating older adults with UUI are lacking.

\section{Sacral Neuromodulation}

Chronic stimulation of the S3 sacral nerve root via sacral neuromodulation (SNM) affects the reflexes between the detrusor, urethral sphincter, and pelvic floor muscles [75]. Chronic neuromodulation therapy requires that an electrode is placed alongside a sacral nerve (usually S3) via the sacral foramen and is connected by cables under the skin to an implanted programmable pulse generator. Implantation of the pulse generator is usually carried out only after a successful trial of either a percutaneous (skin surface) nerve evaluation or Stage I procedure [76]. In a successful trial of SNM, patients should have responded with at least a $50 \%$ improvement in target symptoms for at least 3 days [77]. Several studies [78-80] have shown clinical utility of this therapy in older adults, but the overall paucity of high-quality prospective data on SNM use in elderly patients indicates that continued research is necessary [81•]. Pain at the implant site $(25 \%)$, lead migration (16\%), wound problems (7\%), adverse effect on bowel function (6\%), infection (5\%), and generator problems $(5 \%)$ are common complications. Up to $33 \%$ of patients have required surgical revision of the SNM implant [82].

\section{Magnetic Therapy}

Uninhibited detrusor contractions can be suppressed through magnetic stimulation of the sacral nerve roots [83, 84]. While two prior randomized controlled trials $[83,85]$ showed significant improvement in symptoms of UUI for the magnetic stimulation group compared sham stimulation, a more recent study in elderly women [86] did not find significant difference compared to placebo.

\section{Mechanical Devices}

Several different mechanical devices have been investigated to improve continence. In women, vaginal pessaries or intraurethral plugs may have benefit for individual patients; pessaries need to be managed appropriately to minimize erosion risks, while urethral plugs can increase urinary tract infection rates. A Cochrane review [87••] reported little evidence from controlled trials to judge whether the use of a mechanical device is better than no treatment for the improvement of UI. There was also insufficient evidence to recommend one device over another, or comparing mechanical devices with other treatments.

In men, the penile clamp (Cunningham clamp) can be used to maintain urethral compression. This clamp latches on over the mid shaft of the penis to maintain compression and is often used after radical prostatectomy [88]. Patients are instructed to use up to 2 hours at a time during the day and to leave off at night. Clinicians should confirm that men have the manual dexterity to open and close the clamp and are cognitively intact prior to recommending this therapy [89].

\section{Surgical Treatment}

While data regarding surgical treatment in healthy older adults is increasing, very little remains know about surgical treatment of UI in frail elderly patients $[9 \bullet \bullet$. Morbidity and mortality of UI surgery appear to be similar to major noncardiac surgical procedures [90]. In contrast to younger patients, urodynamics should be performed before considering anti-incontinence surgery in elderly patients $[9 \bullet \bullet]$.

\section{Periurethral Bulking Agents}

Urethral bulking agents are suitable for patients with moderate SUI due to intrinsic sphincter deficiency [7••] or for patients where the risks of a midurethral sling would be considered too great. The effect of bulking agents decreases with time, and repeat injections may be needed to maintain effectiveness. Initial rates of improvement using collagen range from $60-80$ $\%$ at $1-3$ months, but decrease to $50 \%$ at 2 years [91]. Initial improvement rates of $85 \%$ are maintained at 2 years with polydimethylsiloxane [92]. Outcomes seem to be unrelated to age [90]. Use of this therapy is less successful for male SUI, showing only modest success rates and low cure rates [93]. Currently FDA-approved agents in the United States include autologous fat, bovine collagen, calcium hydroxylapatite, carbon beads, and polydimethylsiloxane [50]. 
Slings

Midurethral slings are the most common surgical option offered to treat SUI. Initial short-term data did not show significantly different success rates when comparing elderly women to younger women [94]. More recently, limited evidence suggests that older women may have lower success rates than younger women after the same length of follow-up postoperatively [95]. However, in this cohort, the older women had higher parity and were more likely to have had prior hysterectomy or anti-incontinence surgery potentially confounding the results. The sample size was too small to perform multivariable analysis to assess the impact of these factors on the success rates.

Autologous pubovaginal slings and Burch colposuspension have been used for many years to treat SUI, and may become popular once again for women unwilling to have synthetic mesh used during their reconstructive procedure. While the pubovaginal sling has a higher cure rate, it is also associated with more postoperative urinary tract infections, UUI and voiding dysfunction than the Burch colposuspension [96].

Male slings can be used to treat mild to moderate SUI in men with variable success [6•]. They have gained popularity as they do not require manual manipulation to void. Several authors [97] report very high success rates, but this has not been replicated universally.

\section{Artificial Urethral Sphincters}

Artificial urethral sphincter is the gold standard for surgical treatment of male SUI [6•]. Success rates for bringing high grade incontinence down to one pad per day or less are excellent. Satisfaction rates are also extremely high. Complication rates are low and mechanical failure is uncommon prior to 10 years [6•].

\section{Novel Treatments}

Other therapies showing early promise include intrasphincteric autologous myoblast injections in combination with VES for SUI [98], and individualized physical therapy in elderly patients to improve independence in Activities of Daily Living to decrease UI [99••]

\section{Conclusion}

The prevalence of UI is increasing as the population ages. While many therapies ranging from behavioral and physical therapy modalities to medications and surgical interventions have shown benefit in elderly populations, the data for individual modalities remain limited. Treatment of UI in the elderly should consider the natural history of UI for that specific patient population, comorbid conditions, polypharmacy and treatment goals. More research is needed looking specifically at the efficacy and safety of interventions in the geriatric patient.

Acknowledgements Joy A. Greer is a military service member. This work was prepared as part of her official duties. Title 17, USC, $\mathbb{1 0 5}$ provides that 'Copyright protection under this title is not available for any work of the United States Government.' Title 17, USC, If 101 defines a U.S. Government work as a work prepared by a military service member or employee of the U.S. Government as part of that person's official duties. The views expressed in this article are those of the authors and do not necessarily reflect the official policy or position of the Department of the Navy, Department of Defense, nor the U.S. Government.

Conflict of Interest Joy A. Greer declares that she has no conflict of interest.

Lily A. Arya has received funding through the American Urological Association (AUA) and Pfizer for their joint prospective study on validating instruments.

Ariana L. Smith declares that she has no conflict of interest.

\section{References}

Papers of particular interest, published recently, have been highlighted as:

- Of Importance

•- Of major importance

1. - Haylen BT, de Ridder D, Freeman RM, Swift SE, Berghmans B, Lee J, et al. An International Urogynecological Association (IUGA)/ International Continence Society (ICS) joint report on the terminology for female pelvic floor dysfunction. Int Urogynecol J Pelvic Floor Dysfunct. 2010;21:5-26. This consensus statement provides consistent terminology to enable clinicians to communicate more effectively regarding care of patients with UI.

2. Irwin DE, Milsom I, Hunskaar S, Reilly K, Kopp Z, Herschorn S, et al. Population-based survey of urinary incontinence, overactive bladder, and other lower urinary tract symptoms in five countries: results of the EPIC study. Eur Urol. 2006;50:1306-14. discussion 1314-5.

3. Stewart WF, Van Rooyen JB, Cundiff GW, Abrams P, Herzog AR, Corey R, et al. Prevalence and burden of overactive bladder in the United States. World J Urol. 2003;20:327-36.

4. Brown JS, McGhan WF, Chokroverty S. Comorbidities associated with overactive bladder. Am J Manag Care. 2000;6:S574-9.

5. Hunter KF, Glazener CM, Moore KN. Conservative management for postprostatectomy urinary incontinence. Cochrane Database Syst Rev 20007;(2):CD001843.

6. - Sandhu JS. Treatment options for male stress urinary incontinence. Nat Rev Urol. 2010;7:222-8. This review article succinctly described options for treatment of male SUI to give primary care clinicians an overview when referring patients for specialty treatment.

7. •- Abrams P, Andersson KE, Birder L, Brubaker L, Cardozo L, Chapple C, et al. Fourth International Consultation on Incontinence Recommendations of the International Scientific Committee: Evaluation and treatment of urinary incontinence, pelvic organ prolapse, and fecal incontinence. Neurourol Urodyn. 2010;29:213-40. This consensus statement provides clinicians with algorithms for treating both men and women with UI. 
8. Avery K, Donovan J, Peters TJ, Shaw C, Gotoh M, Abrams P. ICIQ: a brief and robust measure for evaluating the symptoms and impact of urinary incontinence. Neurourol Urodyn. 2004;23:322-30.

9. •- DuBeau CE, Kuchel GA, Johnson 2nd T, Palmer MH, Wagg A. Fourth International Consultation on Incontinence. Incontinence in the frail elderly: Report from the 4th International Consultation on Incontinence. Neurourol Urodyn. 2010;29:165-78. This report highlights important considerations when evaluating and treating UI in frail elderly.

10. Resnick NM, Yalla SV. Management of urinary incontinence in the elderly. N Engl J Med. 1985;313:800-5.

11. Wallace SA, Roe B, Williams K, Palmer M.Bladder training for urinary incontinence in adults. Cochrane Database Syst Rev 2004; (1):CD001308.

12. Subak LL, Whitcomb E, Shen H, Saxton J, Vittinghoff E, Brown JS. Weight loss: a novel and effective treatment for urinary incontinence. J Urol. 2005;174:190-5.

13. Aslan E, Komurcu N, Beji NK, Yalcin O. Bladder training and Kegel exercises for women with urinary complaints living in a rest home. Gerontology. 2008;54:224-31.

14. Fantl JA, Wyman JF, McClish DK, Harkins SW, Elswick RK, Taylor JR, et al. Efficacy of bladder training in older women with urinary incontinence. JAMA. 1991;265:609-13.

15. Alhasso AA, McKinlay J, Patrick K, Stewart L. Anticholinergic drugs versus non-drug active therapies for overactive bladder syndrome in adults. Cochrane Database Syst Rev 2006;(4): CD003193.

16. Godec C, Cass AS, Ayala GF. Bladder inhibition with functional electrical stimulation. Urology. 1975;6:663-6.

17. de Groat WC, Fraser MO, Yoshiyama M, Smerin S, Tai C, Chancellor MB, et al. Neural control of the urethra. Scand J Urol Nephrol Suppl 2001;(207):35-43; discussion 106-25.

18. •- Dumoulin C, Hay-Smith J. Pelvic floor muscle training versus no treatment, or inactive control treatments, for urinary incontinence in women. Cochrane Database Syst Rev. 2010;1:CD005654. This systematic review and meta-analysis with rigorous methodology evaluates the efficacy of PFMT for UI in women.

19. • Campbell SE, Glazener CM, Hunter KF, Cody JD, Moore KN. Cochrane Database Syst Rev.. 2012;1. This systematic review and meta-analysis with rigorous methodology evaluates options such as PFMT for the management of postprostatectomy UI.

20. Burgio KL, Locher JL, Goode PS, Hardin JM, McDowell BJ, Dombrowski $\mathrm{M}$, et al. Behavioral vs drug treatment for urge urinary incontinence in older women: a randomized controlled trial. JAMA. 1998;280:1995-2000.

21. - Herderschee R, Hay-Smith EJ, Herbison GP, Roovers JP, Heineman MJ. Feedback or biofeedback to augment pelvic floor muscle training for urinary incontinence in women. Cochrane Database Syst Rev 2011;(7):CD009252. doi:CD009252. This systematic review and meta-analysis with rigorous methodology evaluates the efficacy of biofeedback and PFMT for UI in women.

22. Brubaker L, Benson JT, Bent A, Clark A, Shott S. Transvaginal electrical stimulation for female urinary incontinence. Am J Obstet Gynecol. 1997; 177:536-40.

23. Alves PG, Nunes FR, Guirro EC. Comparison between two different neuromuscular electrical stimulation protocols for the treatment of female stress urinary incontinence: a randomized controlled trial. Rev Bras Fisioter. 2011;15:393-8.

24. Amaro JL, Gameiro MO, Kawano PR, Padovani CR. Intravaginal electrical stimulation: a randomized, double-blind study on the treatment of mixed urinary incontinence. Acta Obstet Gynecol Scand. 2006;85:619-22.

25. Wang AC, Wang YY, Chen MC. Single-blind, randomized trial of pelvic floor muscle training, biofeedback-assisted pelvic floor muscle training, and electrical stimulation in the management of overactive bladder. Urology. 2004;63:61-6.
26. Pereira VS, de Melo MV, Correia GN, Driusso P. Vaginal cone for postmenopausal women with stress urinary incontinence: randomized, controlled trial. Climacteric. 2012;15:45-51.

27. Roxburgh C, Cook J, Dublin N. Anticholinergic drugs versus other medications for overactive bladder syndrome in adults. Cochrane Database Syst Rev. 2007;4:CD003190.

28. Meek PD, Evang SD, Tadrous M, Roux-Lirange D, Triller DM, Gumustop B. Overactive bladder drugs and constipation: a metaanalysis of randomized, placebo-controlled trials. Dig Dis Sci. 2011;56:7-18.

29. Schiffers M, Sauermann P, Schurch B, Mehnert U. The effect of tolterodine 4 and $8 \mathrm{mg}$ on the heart rate variability in healthy subjects. World J Urol 201;28:651-656.

30. Gopal M, Haynes K, Bellamy SL, Arya LA. Discontinuation rates of anticholinergic medications used for the treatment of lower urinary tract symptoms. Obstet Gynecol. 2008;112:1311-8.

31. Kay G, Crook T, Rekeda L, Lima R, Ebinger U, Arguinzoniz M, et al. Differential effects of the antimuscarinic agents darifenacin and oxybutynin ER on memory in older subjects. Eur Urol. 2006;50:317-26.

32. Kessler TM, Bachmann LM, Minder C, Lohrer D, Umbehr M, Schunemann HJ, et al. Adverse event assessment of antimuscarinics for treating overactive bladder: a network meta-analytic approach. PLoS One. 2011;6:e16718.

33. - Pagoria D, O'Connor RC, Guralnick ML. Antimuscarinic Drugs: Review of the Cognitive Impact When Used to Treat Overactive Bladder in Elderly Patients. Curr Urol Rep. 2011;12:351-7. This systematic review evaluates the cognitive impact of antimuscarinics in elderly.

34. •- Paquette A, Gou P, Tannenbaum C. Systematic review and meta-analysis: do clinical trials testing antimuscarinic agents for overactive bladder adequately measure central nervous system adverse events? J Am Geriatr Soc. 2011;59:1332-9. This meta-analyis highlights the need for improved measures of the impact of antimuscarinics on cognition in geriatric patients.

35. Sand P, Zinner N, Newman D, Lucente V, Dmochowski R, Kelleher $C$, et al. Oxybutynin transdermal system improves the quality of life in adults with overactive bladder: a multicentre, community-based, randomized study. BJU Int. 2007;99:836-44.

36. Sand PK, Johnson Ii TM, Rovner ES, Ellsworth PI, Oefelein MG, Staskin DR. Trospium chloride once-daily extended release is efficacious and tolerated in elderly subjects (aged $>/=75$ years) with overactive bladder syndrome. BJU Int. 2011;107:612-20.

37. Zinner N, Kobashi KC, Ebinger U, Viegas A, Egermark M, Quebe-Fehling E, et al. Darifenacin treatment for overactive bladder in patients who expressed dissatisfaction with prior extended-release antimuscarinic therapy. Int J Clin Pract. 2008; 62:1664-74.

38. • Lackner TE, Wyman JF, McCarthy TC, Monigold M, Davey C. Efficacy of oral extended-release oxybutynin in cognitively impaired older nursing home residents with urge urinary incontinence: a randomized placebo-controlled trial. J Am Med Dir Assoc. 2011;12:639-47. In this trial of antimuscarinics for UUI in elderly subjects with cognitive impairment, oxybutynin did not worsen cognitive function in this 4-week trial. There was, however, no significant improvement in UUI with oxybutynin

39. Gomes T, Juurlink DN, Mamdani MM. Comparative adherence to oxybutynin or tolterodine among older patients. Eur J Clin Pharmacol. 2012;68:97-9.

40. Gomes T, Juurlink DN, Ho JM, Schneeweiss S, Mamdani MM Risk of serious falls associated with oxybutynin and tolterodine: a population based study. J Urol. 2011;186:1340-4.

41. Herschorn S, Pommerville P, Stothers L, Egerdie B, Gajewski J, Carlson K, et al. Tolerability of solifenacin and oxybutynin immediate release in older ( $>65$ years) and younger $(</=65$ years $)$ patients with overactive bladder: sub-analysis from a Canadian, 
randomized, double-blind study. Curr Med Res Opin. 2011; 27:375-82.

42. Kaplan SA, Schneider T, Foote JE, Guan Z, Carlsson M, Gong J. Superior efficacy of fesoterodine over tolterodine extended release with rapid onset: a prospective, head-to-head, placebo-controlled trial. BJU Int. 2011;107:1432-40.

43. Herschorn S, Swift S, Guan Z, Carlsson M, Morrow JD, Brodsky $\mathrm{M}$, et al. Comparison of fesoterodine and tolterodine extended release for the treatment of overactive bladder: a head-to-head placebo-controlled trial. BJU Int. 2010;105:58-66.

44. Scarpero H, Sand PK, Kelleher CJ, Berriman S, Bavendam T, Carlsson M. Long-term safety, tolerability, and efficacy of fesoterodine treatment in men and women with overactive bladder symptoms. Curr Med Res Opin. 2011;27:921-30.

45. Sand PK, Heesakkers J, Kraus SR, Carlsson M, Guan Z, Berriman S. Long-term safety, tolerability and efficacy of fesoterodine in subjects with overactive bladder symptoms stratified by age: pooled analysis of two open-label extension studies. Drugs Aging. 2012;29:119-31.

46. Tyagi P, Tyagi V, Chancellor M. Mirabegron: a safety review. Expert Opin Drug Saf. 2011;10:287-94.

47. Tyagi $\mathrm{P}$, Thomas CA, Yoshimura N, Chancellor MB. Investigations into the presence of functional Beta1, Beta2 and Beta3-adrenoceptors in urothelium and detrusor of human bladder. Int Braz $\mathrm{J}$ Urol. 2009;35:76-83.

48. Chapple C, Wyndaele JJ, Van Kerrebroeck P, et al. Dose-ranging study of once-daily mirabegron (Ym178), A novel selective beta3-adrenoreceptor agonist, in patients with overactive bladder (OAB) 2010;9:249.

49. Chapple CR, Yamaguchi O, Ridder A, et al. Clinical proof of concept study(blossom) shows novel beta 3 adrenoceptor agonist YM178 is effective and well tolerated in the treatment of symptoms of overactive bladder 2008;(Abs 674):239.

50. Elser DM. Stress urinary incontinence and overactive bladder syndrome: current options and new targets for management. Postgrad Med. 2012;124:42-9.

51. Cruz F, Dinis P. Resiniferatoxin and botulinum toxin type A for treatment of lower urinary tract symptoms. Neurourol Urodyn. 2007;26:920-7.

52. Karsenty G, Denys P, Amarenco G, De Seze M, Game X, Haab F, et al. Botulinum toxin A (Botox) intradetrusor injections in adults with neurogenic detrusor overactivity/neurogenic overactive bladder: a systematic literature review. Eur Urol. 2008;53:275-87.

53. Kuo HC, Liao CH, Chung SD. Adverse events of intravesical botulinum toxin a injections for idiopathic detrusor overactivity: risk factors and influence on treatment outcome. Eur Urol. 2010;58:919-26.

54. •- Dmochowski R, Chapple C, Nitti VW, Chancellor M, Everaert K, Thompson C, et al. Efficacy and safety of onabotulinumtoxinA for idiopathic overactive bladder: a double-blind, placebo controlled, randomized, dose ranging trial. J Urol. 2010;184:2416-22. This randomized controlled trial has been cited as the landmark study on dosing of BoNT/A for idiopathic overactive bladder.

55. Bauer RM, Gratzke C, Roosen A, Hocaoglu Y, Mayer ME, Buchner A, et al. Patient-reported side effects of intradetrusor botulinum toxin type a for idiopathic overactive bladder syndrome. Urol Int. 2011;86:68-72.

56. Dowson C, Khan MS, Dasgupta P, Sahai A. Repeat botulinum toxinA injections for treatment of adult detrusor overactivity. Nat Rev Urol. 2010;7:661-7.

57. Duthie J, Wilson DI, Herbison GP, Wilson D. Botulinum toxin injections for adults with overactive bladder syndrome. Cochrane Database Syst Rev. 2007;3:CD005493.

58. Makovey I, Davis T, Guralnick ML, O'Connor RC. Botulinum toxin outcomes for idiopathic overactive bladder stratified by indication: Lack of anticholinergic efficacy versus intolerability. Neurourol Urodyn. 2011;30:1538-40.

59. Denys P, Le Normand L, Ghout I, Costa P, Chartier-Kastler E, Grise $\mathrm{P}$, et al. Efficacy and safety of low doses of onabotulinumtoxinA for the treatment of refractory idiopathic overactive bladder: a multicentre, double-blind, randomised, placebo-controlled doseranging study. Eur Urol. 2012;61:520-9.

60. • Visco AG, Brubaker L, Richter HE, Nygaard I, Paraiso MF, Menefee SA, et al. Anticholinergic therapy vs. onabotulinumtoxina for urgency urinary incontinence. N Engl J Med. 2012;367:1803-13. This trial provides Level 1 evidence for use of BoNT/A earlier in the treatment algorithim for idiopathic UUI.

61. Carr LK. Botulinum toxin A should not be first-line therapy for overactive bladder. Can Urol Assoc J. 2011;5:204-5.

62. Schaffer J, Fantl JA. Urogenital effects of the menopause. Baillieres Clin Obstet Gynaecol. 1996;10:401-17.

63. Lose G, Englev E. Oestradiol-releasing vaginal ring versus oestriol vaginal pessaries in the treatment of bothersome lower urinary tract symptoms. BJOG. 2000;107:1029-34.

64. Cardozo LD, Wise BG, Benness CJ. Vaginal oestradiol for the treatment of lower urinary tract symptoms in postmenopausal women-a double-blind placebo-controlled study. J Obstet Gynaecol. 2001;21:383-5.

65. Zullo MA, Plotti F, Calcagno M, Palaia I, Muzii L, Manci N, et al. Vaginal estrogen therapy and overactive bladder symptoms in postmenopausal patients after a tension-free vaginal tape procedure: a randomized clinical trial. Menopause. 2005;12:421-7.

66. Long CY, Liu CM, Hsu SC, Chen YH, Wu CH, Tsai EM. A randomized comparative study of the effects of oral and topical estrogen therapy on the lower urinary tract of hysterectomized postmenopausal women. Fertil Steril. 2006;85:155-60.

67. MacDiarmid SA, Peters KM, Chen A, Armstrong RB, Orman C, Aquilina JW, et al. Efficacy and safety of extended-release oxybutynin in combination with tamsulosin for treatment of lower urinary tract symptoms in men: randomized, double-blind, placebo-controlled study. Mayo Clin Proc. 2008;83:1002-10.

68. Kaplan SA, Roehrborn CG, Chancellor M, Carlsson M, Bavendam T, Guan Z. Extended-release tolterodine with or without tamsulosin in men with lower urinary tract symptoms and overactive bladder: effects on urinary symptoms assessed by the International Prostate Symptom Score. BJU Int. 2008;102:1133-9.

69. Yamaguchi O, Kakizaki H, Homma Y, Takeda M, Nishizawa O, Gotoh M, et al. Solifenacin as add-on therapy for overactive bladder symptoms in men treated for lower urinary tract symptoms-ASSIST, randomized controlled study. Urology. 2011;78:126-33.

70. Peters KM, Macdiarmid SA, Wooldridge LS, Leong FC, Shobeiri SA, Rovner ES, et al. Randomized trial of percutaneous tibial nerve stimulation versus extended-release tolterodine: results from the overactive bladder innovative therapy trial. J Urol. 2009;182:1055-61.

71. Kohli N, Rosenblatt PL. Neuromodulation techniques for the treatment of the overactive bladder. Clin Obstet Gynecol. 2002;45:218-32.

72. Peters KM, Carrico DJ, Perez-Marrero RA, Khan AU, Wooldridge LS, Davis GL, et al. Randomized trial of percutaneous tibial nerve stimulation versus Sham efficacy in the treatment of overactive bladder syndrome: results from the SUmiT trial. J Urol. 2010; 183:1438-43.

73. Schreiner L, dos Santos TG, Knorst MR, da Silva Filho IG. Randomized trial of transcutaneous tibial nerve stimulation to treat urge urinary incontinence in older women. Int Urogynecol J Pelvic Floor Dysfunct. 2010;21:1065-70.

74. - Burton C, Sajja A, Latthe PM. Effectiveness of percutaneous posterior tibial nerve stimulation for overactive bladder: a systematic review and meta-analysis. Neurourol Urodyn. 2012;31:120616. This meta-analysis shows that PTNS is comparable to medication management for short-term treatment of $O A B$.

75. Occhino JA, Siegel SW. Sacral nerve modulation in overactive bladder. Curr Urol Rep. 2010;11:348-52.

76. Herbison GP, Arnold EP. Sacral neuromodulation with implanted devices for urinary storage and voiding dysfunction in adults. Cochrane Database Syst Rev. 2009;2:CD004202. 
77. Siegel SW, Catanzaro F, Dijkema HE, Elhilali MM, Fowler CJ, Gajewski JB, et al. Long-term results of a multicenter study on sacral nerve stimulation for treatment of urinary urge incontinence, urgency-frequency, and retention. Urology. 2000;56:87-91.

78. Edlund C, Dijkema HE, Hassouna MM, Van Kerrebroeck PE, Peeker R, Van den Hombergh U, et al. Sacral nerve stimulation for refractory urge symptoms in elderly patients. Scand J Urol Nephrol. 2004;38:131-5.

79. Amundsen CL, Webster GD. Sacral neuromodulation in an older, urge-incontinent population. Am J Obstet Gynecol. 2002;187:14625. discussion 1465.

80. White WM, Mobley 3rd JD, Doggweiler R, Dobmeyer-Dittrich C, Klein FA. Sacral nerve stimulation for refractory overactive bladder in the elderly population. J Urol. 2009;182:1449-52.

81. Griebling TL. Sacral nerve stimulation in the elderly. Int Urogynecol J. 2010;21 Suppl 2:S485-9. This review reports the available data on SNM in geriatric patients.

82. Brazzelli M, Murray A, Fraser C. Efficacy and safety of sacral nerve stimulation for urinary urge incontinence: a systematic review. J Urol. 2006;175:835-41.

83. Fujishiro T, Takahashi S, Enomoto H, Ugawa Y, Ueno S, Kitamura T. Magnetic stimulation of the sacral roots for the treatment of urinary frequency and urge incontinence: an investigational study and placebo controlled trial. J Urol. 2002;168:1036-9.

84. McFarlane JP, Foley SJ, de Winter P, Shah PJ, Craggs MD. Acute suppression of idiopathic detrusor instability with magnetic stimulation of the sacral nerve roots. Br J Urol. 1997;80:734-41.

85. But I, Faganelj M, Sostaric A. Functional magnetic stimulation for mixed urinary incontinence. J Urol. 2005;173:1644-6.

86. Wallis MC, Davies EA, Thalib L, Griffiths S. Pelvic static magnetic stimulation to control urinary incontinence in older women: a randomized controlled trial. Clin Med Res. 2012;10:7-14.

87. • Lipp A, Shaw C, Glavind K. Mechanical devices for urinary incontinence in women. Cochrane Database Syst Rev 2011;(7):CD001756. This systematic review and meta-analysis with rigorous methodology evaluates the efficacy of mechanical devices for UI in women.

88. Moore KN, Schieman S, Ackerman T, Dzus HY, Metcalfe JB, Voaklander DC. Assessing comfort, safety, and patient satisfaction with three commonly used penile compression devices. Urology. 2004;63:150-4.

89. Vaughan CP, Goode PS, Burgio KL, Markland AD. Urinary incontinence in older adults. Mt Sinai J Med. 2011;78:558-70.

90. Griebling T. Geriatric urology In: Solomon DH, LoCicero L, Rosenthal R (eds) New Frontiers in Geriatric Research. American Geriatric Society, 2004. pp 269-302.

91. Monga AK, Robinson D, Stanton SL. Periurethral collagen injections for genuine stress incontinence: a 2-year follow-up. Br J Urol. 1995;76:156-60.

92. Ghoniem G, Corcos J, Comiter C, Westney OL, Herschorn S. Durability of urethral bulking agent injection for female stress urinary incontinence: 2-year multicenter study results. J Urol. 2010;183:1444-9.

93. Herschorn S, Bruschini H, Comiter C, Grise P, Hanus T, Kirschner-Hermanns R, et al. Surgical treatment of stress incontinence in men. Neurourol Urodyn. 2010;29:179-90.

94. Ku JH, Oh JG, Shin JW, Kim SW, Paick JS. Age is not a limiting factor for midurethral sling procedures in the elderly with urinary incontinence. Gynecol Obstet Invest. 2006;61:194-9.

95. Kim J, Lucioni A, Govier F, Kobashi K. Worse long-term surgical outcomes in elderly patients undergoing SPARC retropubic midurethral sling placement. BJU Int. 2011;108:708-12.

96. Albo ME, Richter HE, Brubaker L, Norton P, Kraus SR, Zimmern PE, et al. Burch colposuspension versus fascial sling to reduce urinary stress incontinence. N Engl J Med. 2007; 356:2143-55.

97. Comiter CV. Male incontinence surgery in the 21 st century: past, present, and future. Curr Opin Urol. 2010;20:302-8.

98. Blaganje M, Lukanovic A. Intrasphincteric autologous myoblast injections with electrical stimulation for stress urinary incontinence. Int J Gynaecol Obstet. 2012;117:164-7.

99. •- Vinsnes AG, Helbostad JL, Nyronning S, Harkless GE, Granbo R, Seim A. Effect of physical training on urinary incontinence: a randomized parallel group trial in nursing homes. Clin Interv Aging. 2012;7:45-50. This trial highlights the importance of treating co-existing conditions, specifically decreased activities of daily living, to improve UI. 